\title{
Postural Mechanisms That Maintain Airway Adequacy In Obstructive Sleep Apnoea As Determined By Magnetic Resonance Imaging
}

\author{
Suat Avcı ${ }^{1}$, Aynur Yılmaz Avcı ${ }^{2}$ \\ 1 Department of Otolaryngology, Faculty of Medicine, Başkent University, Ankara, Turkey \\ 2 Department of Neurology, Faculty of Medicine, Başkent University, Ankara, Turkey
}

\begin{abstract}
Objective: This magnetic resonance imaging (MRI) study aimed to explored associations between neutral head posture, size, and shape of the pharyngeal airway and the severity of obstructive sleep apnoea (OSA).

Methods: A retrospective methodology was used to study 90 male patients who had already undergone overnight polysomnography and cervical MRI. 60 cases of OSA were compared with a control group of 30 mild OSA (or straightforward snoring) cases in terms of MRI, with the aim to examine how neutral head posture, the pharynx and the adjacent anatomical structures interact. MRI was performed in all cases with the patient supine and head held in neutral position. Measurements were taken of the Craniocervical extension (CCE) and epiglot angle, length of the tongue root, distance between the hyoid and the plane of the mandible (MP-H distance), and the diameter of the pharyngeal airway at seven points were measured.
\end{abstract}

Results: Differences in shape were more perceptible at the caudal levels. In the OSA group, the shapes were more oblique. The retroglossal level was where the largest shape difference was apparent. After adjusting for body mass index and age, neutral head posture was correlated with OSA severity. There was a correlation between CCE and lengthening of the tongue root, MP-H distance, epiglot angle, and the two most caudal airway areas.

Conclusions: Overall, increased length of the root of the tongue, MP-H distance, and epiglot angle are associated with CCE in OSA patients and resulted in a larger and more oblique airway in the majority of caudal planes. Such an alteration may be viewed as an adaptation in posture designed to keep the airway sufficiently open in patients suffering from OSA.

Keywords: Obstructive sleep apnea, magnetic resonance imaging, neutral head posture, pharyngeal airway

\section{Introduction}

Obstructive sleep apnoea (OSA) is a condition in which air ceases to pass through the airway even while there are the movements of breathing. The airflow is interrupted by a physical obstruction, such as a partially collapsing oropharynx, and affects the velum, dorsal tongue and rear wall of the pharynx. ${ }^{[1,2]}$

There are a number of imaging techniques which can be employed to visualise and measure the airway within the pharynx, with a corresponding range of benefits and drawbacks. These include: nasopharyngoscopy, cephalometrics, computed tomography (CT), magnetic resonance imaging (MRI), and cone-beam computed tomography (CBCT). ${ }^{[3-}$ 9] The airway can be measured with a high degree of accuracy using cephalometry, but only within the sagittal plane, not transversely. ${ }^{[10]}$ Both CT and MRI can be employed
Correspondence: Dr. Suat Avc1, Department of Otolaryngology, Başkent University Hospital. Saray Mah. Yunusemre Cad. No. 1, Alanya 07400 Antalya, Turkey e-mail: suat_avci2002@yahoo.com

Received: 1st, September, 2018; Accepted: 10th, December, 2018
Online available at: www.entupdates.org

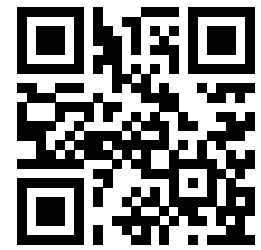


to measure both sagitally and tranversely, as well as find airway cross-sectional areas, but are complicated to interpret as a whole since thickness of the slices taken and their direction vary, and it is difficult to precisely localise where a section was taken.

A different study from ours that looked at OSA cases and employed 2D cephalometry to examine the head held in a natural position (NHP) whilst standing, reported that the cranio-cervical angle (CC) was greatly raised in such individuals and generally came about from the cervical spine being bent forwards. ${ }^{[10]} \mathrm{A}$ study with $3 \mathrm{D}$ techniques revealed that, when CBCT was carried out with the head held neutrally (i.e. NHP), the head tended to be in an extended position and held forward, leading to increased measurements of airway dimensions and greater cross-sectional area at the level of the hyoid bone. ${ }^{[11]}$ The conclusions from that study are in line with other reports in the literature. ${ }^{[10,12]}$

So far as the authors are aware, there is no previous research concerning postural protective mechanisms in OSA patients and employing MRI with the patient in a neutral posture. In the present study, the patients remained supine throughout axial MRI, with their heads held in a neutral position, to allow for consistency in the subjects' position. We hypothesized that, whilst MRI was being performed, OSA patients' postural protective mechanisms are in play and are visualisable and measurable in three different axes. We examined the size and shape of the airway, CC inclination angle, and related pharyngeal airway parameters such as the length of the root of the tongue, distance between the hyoid and the plane of the mandible (MP-H distance), and epiglot angle, which serve to reveal postural protective mechanisms in action.

The aim of this study was to describe the size and shape at seven different points, identified anatomically, within the pharynx, to identify the level at which size and shape most differ between OSA cases and the control cases. We aimed to identify any correlations amongst OSA severity, $\mathrm{CC}$ inclination angle, and other related protective mechanisms involving posture.

\section{Materials and methods}

\section{Subjects}

This study retrospectively examined imaging results from 90 male patients who underwent polysomnography (PSG) in our sleep laboratory between 2014 and 2018.90 patients who had undergone ear, nose, and throat examinations and had cervical MRI for the assessment of the upper airway structures in the course of their diagnostic workup were selected for the study. Although some of our subjects have been included in other published research, the findings concerning the CC inclination angle in the present study have not been reported elsewhere. The local institutional ethical review panel decided the present study, based on a retrospective methodology, did not require ethical approval to proceed.

All the cases had a full history taken and were examined physically as well as assessed by ENT. The workup included calculation of body-mass index (BMI), endoscopic examination in the upright position of the awake patient using a fibreoptic endoscope, polysomnography and MRI of the upper airway. Cases who were below 18 years old or over 69 were excluded from the study, as were those on longterm pharmacotherapy that influences the tone of the upper airway (such as benzodiazepines or sedating agents), those whose main diagnosis was central sleep apnoea according to PSG, those with chronic organ failure of the kidneys, heart or liver, or reduced pulmonary function, and all other sleep disorder sufferers. The apnoea-hypopnoea index $(\mathrm{AHI})$ was used to sort the cases into three groups: (1) $\mathrm{AHI} \leq 10$, (2) $\mathrm{AHI} 10$ to $\leq 30$, and (3) $\mathrm{AHI}>30$. Each of these groups contained 30 cases, the first group acting as the control group.

\section{Polysomnography}

Baskent University Alanya Hospital Chest Disease Sleep Laboratory performed polysomnography on all 90 cases, by means of a computerised PSG device (E series, 44 channels; Compumedics, Victoria, Australia). The American Academy of Sleep Medicine criteria ${ }^{[13,14]}$ were used to stage sleep.

\section{Magnetic resonance imaging}

A Bravo MRI 355 1.5 T machine (GE, Fairfield, CT, USA) with a quadrature head coil was used to acquire MRI images. T1-weighted MRI with 3D fast spoiled gradient-echo (SPGR: TR/TE/FA, 6.2/1.8/12 ms; FOV, $254 \times 254 \mathrm{~mm}$; matrix, $186 \times 186$; NEX, 2) was used to acquire sections in the axial plane. The region between the nasion and the epiglottic base (i.e. vallecula) was divided into slices of $1.2 \mathrm{~mm}$ thickness. All the cases remained supine throughout axial MRI acquisition, with NPH, to guarantee consistency in position. All cases were awake and their breathing was tidal. 


\section{Anatomical definitions, measurements, and analysis}

The images were sorted and measurements of the airway and craniofacial structures were recorded by an Otolaryngology specialist (SA), who repeated each measurement on a minimum of 3 occasions to enhance reliability. An image-processing application (AW Volume Share 5; GE) was used on a workstation for all processing of MRI data; Measurements performed linearly were to the nearest millimeter. Prior to the measurement phase, seven planes were chosen to act as reference points. The A plane was at the level of the bony palate, whilst planes B and C planes were in parallel with A although 10 and $20 \mathrm{~mm}$ inferior. The $\mathrm{D}$ plane was at the level where the airway is most restricted, i.e. with the uvula anteriorly and the pharyngeal wall posteriorly. The E plane likewise traverses an area of airway narrowing, i.e. the space between the tongue dorsum anteriorly and pharyngeal wall posteriorly. The $\mathrm{F}$ plane corresponded to the tip of the epiglottis, with the G plane corresponding to the base of the epiglottis. For each plane so defined, the dimensions were noted for the cross section on sagittal and axial view (Fig. 1). Measured dimensions for the various anatomical structures were then placed into one of the following two domains (Table 1):

\section{(1) Midsagittal parameters (Fig. 1a)}

11 landmarks altogether were highlighted on midsagittal sections. Two lines were drawn and the mandibular plane was marked. Within the sagittal sections, two linear parameters (MP-H distance and Valperp length) and two angular parameters $\left(\alpha_{1}\right.$ and $\left.\alpha_{2}\right)$ were measured.

\section{(2) Cross-sectional airway parameters (Fig. 1b)}

The size of the airway at the various levels delimited by planes $A$ to $G$ was calculated from serial measurements, including seven lots of lateral and anteroposterior size measurements and an equal number of latd/apd ratios (giving information about the profile of the airway in cross section, as well as CSAs.

Table 1. Definitions of parameters

\begin{tabular}{|c|c|c|c|}
\hline $\begin{array}{l}\text { Symbol } \\
\text { Axial cro }\end{array}$ & $\begin{array}{l}\text { Type } \\
\text { al parameters }\end{array}$ & Unit & Definition \\
\hline latd & $1 \mathrm{D}$ & $\mathrm{mm}$ & Lateral dimension of the airway \\
\hline apd & $1 \mathrm{D}$ & $\mathrm{mm}$ & Antero-posterior dimension of the airway \\
\hline$R_{1}$ & Alatd/Aapd & Ratio & Ratio of lateral and AP airway dimensions at the A plane \\
\hline$R_{2}$ & Blatd/Bapd & Ratio & Ratio of lateral and AP airway dimensions at the B plane \\
\hline$R_{3}$ & Clatd/Capd & Ratio & Ratio of lateral and AP airway dimensions at the C plane \\
\hline$R_{4}$ & Dlatd/Capd & Ratio & Ratio of lateral and AP airway dimensions at the D plane \\
\hline$R_{5}$ & Elatd/Eapd & Ratio & Ratio of lateral and AP airway dimensions at the E plane \\
\hline$R_{6}$ & Flatd/Fapd & Ratio & Ratio of lateral and AP airway dimensions at the F plane \\
\hline$R_{7}$ & Glatd/Gapd & Ratio & Ratio of lateral and AP airway dimensions at the G plane \\
\hline CSA & $2 \mathrm{D}$ & $\mathrm{mm}^{2}$ & Cross-sectional area of the airway in the A, B, C, D, E, F, G planes \\
\hline \multicolumn{4}{|c|}{ Midsagittal parameters (indicators of postural protective mechanism) } \\
\hline Valperp & $1 \mathrm{D}$ & $\mathrm{mm}$ & $\begin{array}{l}\text { Tongue base length (Distance between the perpendicular to the TTip line at the } \\
\text { thickest point of the tongue and vallecula) }\end{array}$ \\
\hline$M P-H$ & $1 \mathrm{D}$ & $\mathrm{mm}$ & Length from the mandibular plane to the HY bone \\
\hline$\alpha_{1}$ & Angular & $\circ$ & Odontoid process tangent/nasion-sella line angle (craniocervical inclination) \\
\hline$\alpha_{2}$ & Angular & o & Epiglot angle \\
\hline
\end{tabular}




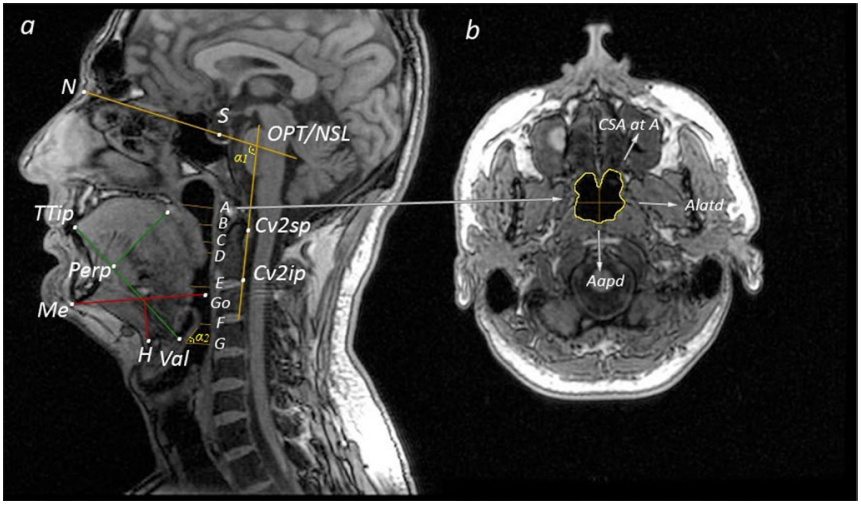

Fig 1. (a) The $A, B, C, D, E, F$, and $G$ planes on mid-sagittal magnetic resonance imaging (MRI). Craniofacial landmarks: $\mathrm{N}$, nasion; $\mathrm{S}$, sella; $\mathrm{H}$; furthest portion of hyoid (HY) bone anteriorly; Val, vallecula; Me, menton; Go, gonion; TTip, the tip of the tongue; Perp, perpendicular to the $\mathrm{Val}-\mathrm{TTip}$ line at the thickest point of the tongue. Measurements: MP-H distance, minimum measured length between the mandibular plane (Go-Me) and the HY bone; Valperp distance, length of the base of the tongue; odontoid process tangent/nasion-sella line (OPT/NSL) angle ( $\alpha 1$ ), angle between the odontoid process tangent, which passes through Cv2sp (the superior posterior point of the second cervical vertebra) and Cv2ip (the inferior posterior point of the second cervical vertebra), and the NSL; $\alpha 2$, epiglot angle. (b) Axial cross-section of the A plane. Airway dimensions: apd, anteroposterior dimension; latd, lateral dimension. Airway area is the cross-sectional area (CSA).

\section{Statistical analysis}

Descriptive statistics, including the mean, standard deviation, $\mathrm{n}$ and percentiles, were obtained for both discrete and continuous variables. Alongside these statistics, the homogeneity of variance, an essential parametric test, was determined by means of Levene's test. The Shapiro-Wilk test was used to detect how normal the data were. In comparing the two groups for differences, for parametric data Student's t-test was employed, and the Mann-Whitney U test was used for non-parametric data. In the calculation of differences between at least three groups, parametric data were tested by one-way analysis of variance, non-parametric data being tested by the Kruskal-Wallis test. If a minimum of three groups were being compared, the Bonferroni correction for multiple comparisons was used. The relationship between two continuous variables was assessed using the Pearson correlation coefficient, or the Spearman correlation coefficient when the data were unsuitable for parametric tests. Once the effects of age and BMI had been controlled for, partial correlation coefficient analysis was employed to explore the linear relationship between

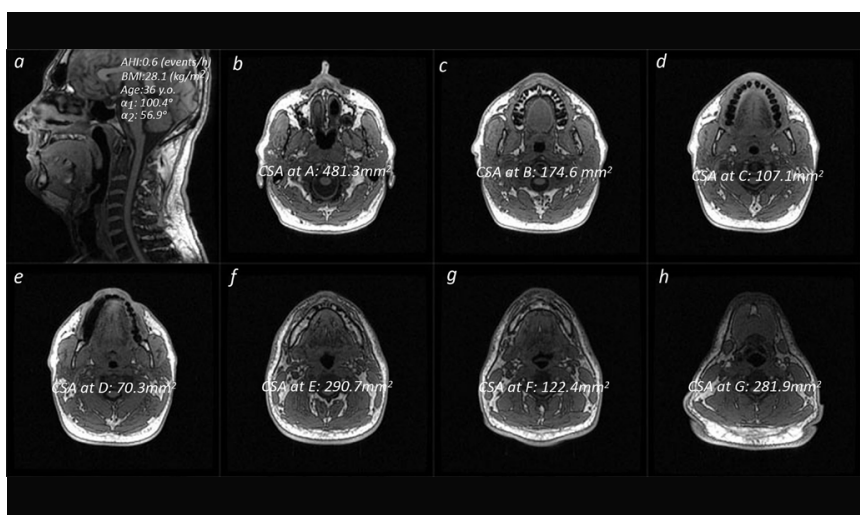

Fig 2. T1-weighted MRI scans from a normal subject. (a) Midsagittal and in transverse sections, (b) A plane, (c) B plane, (d) C plane, (e) D plane (f) E plane (g) F plane, and (h) G plane. Apnea-hypopnea index (AHI) score, body mass index (BMI), age, $\alpha 1, \alpha 2$ angles, and CSAs are marked on the image. Note CSA in the A plane is larger than in the other planes. Both the head and tongue appear unstrained.

the odontoid process tangent/nasion-sella line (OPT/ NSL) and other variables. The SPSS application was used for data analysis (version 25.0; IBM Corp., Armonk, NY, USA). Values for p below 0.05 and below 0.01 were taken to indicate a statistically significant result.

\section{Results}

Table 2 shows the patient characteristics and parameters by OSA category. The control group had a lower mean weight $(\mathrm{AHI} \leq 10)$ than the cases group $(\mathrm{p}<0.001)$. Parameters showing hypopnoea $\left(\mathrm{min} \mathrm{SaO}_{2}\right.$ and $\mathrm{ST}_{90}$ ) differed between groups at the level of statistical significance $(\mathrm{p}<0.001)$. The $\mathrm{R}_{3}, \mathrm{R}_{4}, \mathrm{R}_{5}$, and $\mathrm{R}_{6}$ values (see Table 1 ) were significantly less for the cases than the controls. The CSA in the A and $\mathrm{D}$ planes was higher in the control group than in the OSA groups ( $\mathrm{p}<0.01$ and 0.001 respectively). However, the CSA at $\mathrm{F}$ was larger in the severe OSA group than in any other group $(\mathrm{p}<0.03)$. The Valperp and MP-H dimensions were longer, and the $\alpha_{1}$ and $\alpha_{2}$ angles larger, in the severe OSA group than in the other groups $(\mathrm{p}<0.001)$ (Table 2). Parameters related to AHI and hypoxia showed correlation with the $\alpha_{1}$ angle. Simple correlation analysis showed that the $\alpha_{1}$ angle was inversely correlated with $\mathrm{R}_{3}$, $\mathrm{R}_{4}, \mathrm{R}_{5}$, and $\mathrm{R}_{6}$, and positively corelated with CSA in the $\mathrm{E}$, $\mathrm{F}$, and $\mathrm{G}$ planes, and with the valperp, MP-H distance, and $\alpha_{2}$ angle. When adjusted for age and BMI, $\alpha_{1}$ was correlated with CSA in the $\mathrm{E}$ and $\mathrm{G}$ planes, and with the Valperp, MP-H distance, and $\alpha_{2}$ (see Table 3). 
Table 2. Comparison of patient characteristics by OSA severity category

\begin{tabular}{|c|c|c|c|c|}
\hline & $\begin{array}{c}\text { Control }(A H I \leq 10) \\
\qquad n=30\end{array}$ & $\begin{array}{l}\text { Mild and Moderate OSA }(10<\mathrm{AHI} \leq 30 \\
\qquad \mathrm{N}=30\end{array}$ & $\begin{array}{l}\text { Severe OSA }(A H I>30) \\
\qquad N=30\end{array}$ & p \\
\hline Age (years) & $41.47 \pm 9.43$ & $41.37 \pm 6.73$ & $39.13 \pm 5.07$ & NS \\
\hline$A H I$ (events/h) & $4.75 \pm 3.22^{\mathrm{ab}}$ & $19.67 \pm 4.89^{b}$ & $59.12 \pm 19.82$ & $0.001 * *$ \\
\hline$B M I\left(k g / m^{2}\right)$ & $27.95 \pm 3.74^{\mathrm{ab}}$ & $30.36 \pm 3.49$ & $31.09 \pm 3.56$ & 0.001 ** \\
\hline Min $\mathrm{SaO}_{2}(\%)$ & $88.2 \pm 261^{a b}$ & $84.3 \pm 5.4^{b}$ & $77.67 \pm 7.98$ & $0.001 * *$ \\
\hline$S T_{90}(\min )$ & $0.63 \pm 1.1^{\mathrm{ab}}$ & $4.51 \pm 6.47^{b}$ & $54.93 \pm 72.25$ & $0.001 * *$ \\
\hline ESS & $8.5 \pm 5.12$ & $11.73 \pm 5.45$ & $10.5 \pm 6.03$ & NS \\
\hline$R_{1}$ & $1.25 \pm 0.27$ & $1.41 \pm 0.44$ & $1.4 \pm 0.44$ & NS \\
\hline$R_{2}$ & $1.98 \pm 0.9$ & $1.6 \pm 0.45$ & $1.63 \pm 1.09$ & NS \\
\hline$R_{3}$ & $2.84 \pm 1.5^{a b}$ & $2.18 \pm 1.12$ & $2.03 \pm 1.27$ & $0.04 *$ \\
\hline$R_{4}$ & $3.26 \pm 3.5^{\mathrm{ab}}$ & $1.96 \pm 1.2$ & $1.86 \pm 1.73$ & $0.04 *$ \\
\hline$R_{5}$ & $2.11 \pm 0.8^{\mathrm{ab}}$ & $1.59 \pm 0.55$ & $1.54 \pm 0.73$ & 0.001 ** \\
\hline$R_{6}$ & $2.34 \pm 0.98^{\mathrm{ab}}$ & $1.8 \pm 0.59$ & $1.74 \pm 0.83$ & 0.01 * \\
\hline$R_{7}$ & $1.74 \pm 0.36$ & $1.5 \pm 0.41$ & $1.61 \pm 0.82$ & NS \\
\hline CSA at $A$ & $479.79 \pm 127.74 \mathrm{ab}$ & $394.68 \pm 106.11$ & $403.68 \pm 108.08$ & 0.01 * \\
\hline CSA at $B$ & $165.92 \pm 64.74$ & $139.1 \pm 57.41$ & $142.8 \pm 67.66$ & NS \\
\hline CSA at $C$ & $108.3 \pm 63.67$ & $83.32 \pm 42.5$ & $81.76 \pm 54.5$ & NS \\
\hline CSA at $D$ & $79.7 \pm 46.65^{\mathrm{ab}}$ & $50.88 \pm 23.99$ & $48.1 \pm 26.1$ & $0.001 * *$ \\
\hline CSA at $E$ & $295.75 \pm 96.32$ & $282.41 \pm 91.57$ & $330.59 \pm 130.74$ & NS \\
\hline CSA at $F$ & $113.26 \pm 54.64^{b}$ & $111.09 \pm 44.84^{b}$ & $151.15 \pm 88.36$ & $0.03 *$ \\
\hline CSA at $G$ & $266.42 \pm 62.93$ & $287.55 \pm 66.86$ & $298.19 \pm 101.79$ & NS \\
\hline Valperp & $51.46 \pm 6.69^{b}$ & $50.28 \pm 7.92^{b}$ & $56.67 \pm 7.6$ & $0.001 * *$ \\
\hline$M P-H$ & $20.69 \pm 6.1^{b}$ & $21.28 \pm 4.98^{b}$ & $27.39 \pm 6.12$ & $0.001 * *$ \\
\hline$\alpha_{1}$ & $100.53 \pm 5.05^{b}$ & $101.1 \pm 5.73^{b}$ & $105.4 \pm 5.06$ & $0.001 * *$ \\
\hline$\alpha_{2}$ & $70.86 \pm 8.77^{b}$ & $68.92 \pm 9.3^{b}$ & $80.23 \pm 11.59$ & $0.001 * *$ \\
\hline
\end{tabular}

Data are means \pm standard deviation

$A H I$, apnea-hypopnea index; $\min \mathrm{SaO}_{2}$ lowest oxygen saturation; $S T_{90}$, total sleep time with oxygen saturation < $90 \%$; ESS, Epworth Sleepiness Scale; $B M I$, body mass index; NS, not significant. Other abbreviations are the same as in Table 1.

${ }^{*} \mathrm{p}<0.05,{ }^{*} \mathrm{p}<0.01$

a Different from $\mathrm{AHI} 10$ and $\leq 30$

${ }^{b}$ Different from $\mathrm{AHI}>30$

\section{Discussion}

The results of this study add to knowledge about the postural protective mechanisms in awake supine OSA patients with a neutral head position. First, the $\alpha_{1}$ angle in a neutral head position is associated with OSA severity. Second, the $\alpha_{1}$ angle has an association with increased CSA of the airway caudally (in the $\mathrm{E}$ and $\mathrm{G}$ planes). Third, extension of the $\alpha_{1}$ angle is associated with an increase in the MP-H distance, the length of the root of the tongue, and the epiglot angle. 
Table 3. Simple and partial correlations between $\alpha 1$ angle and other parameters

\begin{tabular}{|c|c|c|}
\hline & $\begin{array}{l}\alpha_{1} \\
r(p)\end{array}$ & $\begin{array}{l}\alpha_{1} \text { (adjusted for BMI, } \\
\text { age) } \\
r(p)\end{array}$ \\
\hline Age & -0.147 (NS) & \\
\hline$B M I$ & $0.215^{*}(0.042)$ & \\
\hline$A H I$ & $0.414^{* \star}(0.000)$ & $0.342 * *(0.001)$ \\
\hline $\mathrm{Min} \mathrm{SaO}_{2}$ & $-0.331^{\star \star}(0.001)$ & $-0.270 *(0.011)$ \\
\hline$S T_{90}$ & $0.372^{* \star}(0.000)$ & $0.301 * *(0.004)$ \\
\hline ESS & -0.109 (NS) & -0.116 (NS) \\
\hline$R_{1}$ & 0.160 (NS) & 0.143 (NS) \\
\hline$R_{2}$ & -0.036 (NS) & -0.005 (NS) \\
\hline$R_{3}$ & $-0.211^{*}(0.046)$ & -0.130 (NS) \\
\hline$R_{4}$ & $-0.210^{*}(0.047)$ & -0.153 (NS) \\
\hline$R_{5}$ & $-0.245^{*}(0.020)$ & -0.133 (NS) \\
\hline$R_{6}$ & $-0.240^{*}(0.023)$ & -0.109 (NS) \\
\hline$R_{7}$ & -0.138 (NS) & -0.042 (NS) \\
\hline CSA at $A$ & -0.099 (NS) & 0.040 (NS) \\
\hline CSA at $B$ & -0.088 (NS) & -0.004 (NS) \\
\hline CSA at C & 0.068 (NS) & 0.147 (NS) \\
\hline CSA at $D$ & 0.051 (NS) & 0.168 (NS) \\
\hline CSA at $E$ & $0.314^{* *}(0.003)$ & $0.292 * *(0.006)$ \\
\hline CSA at $F$ & $0.228^{*}(0.030)$ & 0.163 (NS) \\
\hline CSA at $G$ & $0.325^{* *}(0.002)$ & $0.277^{* *}(0.009)$ \\
\hline Valperp & $0.291^{* \star}(0.005)$ & $0.249 *(0.019)$ \\
\hline$M P-H$ & $0.290^{* *}(0.006)$ & $0.256 *(0.016)$ \\
\hline$\alpha_{2}$ & $0.362^{* \star}(0.000)$ & $0.310 * *(0.003)$ \\
\hline
\end{tabular}

$A H I$, apnea-hypopnea index; $\min \mathrm{SaO}_{2}$ lowest oxygen saturation; $S T_{90}$ total sleep time with oxygen saturation < $90 \%$; ESS, Epworth sleepiness scale; $B M I$, body mass index; NS, not significant. Other abbreviations are the same as in Table 1.

${ }^{*} p<0.05,{ }^{* *} p<0.01$

\section{Study limitations}

In the present study, the heads of the patients were positioned neutrally. However, a position perpendicular to the Frankfort plane is the posture most commonly adopted for MRI studies involving OSA. In the past, many researchers have achieved this position during MRI by means of air pillows. However, for such MRI studies, it took from 3 to 5 minutes to acquire the images. ${ }^{[15-17]}$ Despite attempts to get the imaging subjects to avoid moving, swallowing, or talking, and to breathe quietly through the nose during the procedure, it is likely that the influence of such actions on the results could not be completely eliminated. ${ }^{[18]}$ Furthermore, some patients do not tolerate this position because of individual variations in posture or neck problems, and a neutral head position should accordingly be recommended to ensure consistent head positioning during MRI. In addition, even in a perpendicular position, pillow height may affect FHP in the supine position.

Second, in this study, MRI imaging was performed on patients who were fully awake. It is probable that when the upper portion of the airway becomes obstructed, there is a compensatory physiological adjustment, in other words, the patient extends his/her head relative to the cervical vertebrae. ${ }^{[10]}$ It is still unknown exactly in what way the measurements taken in fully conscious patients lying supine and holding their head neutrally should be related to the OSA severity measurements obtained when subjects are sleeping, with their heads in a variety of poses constrained by elements such as the sleeping position and the height of any pillows. ${ }^{[12]}$ The fact that NHP and OSA are clearly associated, as proven by by Solow et al. (1993) and corroborated by Tangugsorn et al. (1995a), as well as demonstrated by the present study, highlights particular physiological and anatomical characteristics which lead to ongoing respiratory difficulty at night even when patients are not sleeping. $[19,20]$

In spite of the patients' keeping their heads held neutrally and remaining awake in this retrospective MRI study, we noted the presence of protective postural mechanisms in the cases group. Earlier research employing 2D cephalometry led to the observation that the principal physiological adaptations in posture supporting the maintenance of an adequate airway in cases of OSA who were both awake and upright were CCE and FHP; greater length of tongue, a hyoid bone that was lower in relation to the MP, and greater diametric measurements for the three most caudal airways, i.e., the uvula, radix linguae, and epiglottis, were seen to be an advantage to such cases. ${ }^{[10,12]}$ However, these studies offered no data pertaining to the axial cross-sectional diameter of the subjects' airways

A recent 3D study demonstrated that if CBCT was undertaken in subjects with a neutral head posture (NHP), head posture, pharyngeal airway distance, and CSA at the 
HY level were found to be definitely interrelated: an increase in FHP had an association with raised values for the airway distance and CSA at the HY level. ${ }^{[1]}$ These findings are in line with the literature published up to now. ${ }^{[10,}$ ${ }^{12]}$ Furthermore, a CBCT study of patients in which the standardized head position was used revealed no association between head posture and the volume of the airway within the pharynx; the sole relationship identified was between pharyngeal airway distance and CSA. ${ }^{[1]}$ These findings suggested that the adaptations in physiological posture that keep the airway sufficiently patent in OSA patients may be attributable to the airway within the pharynx undergoing elongation at the level of the hyoid, rather than to the volume of the airway having expanded. If the airway within the pharynx is distended and the head is held forward, there may be less risk of the airway collapsing as a result of alterations to the pharyngeal airway dimensions and pressure within the lumen at the level of the hyoid whilst breathing in. It had previously been supposed that this could best be accounted for by the volume of the airway having enlarged. ${ }^{[10,16]}$ It is worth noting, however, that the earlier research aimed to compare OSA patients who had morphological deviations in the upper cervical spine with those that lacked such a feature.

\section{Correlations between $\alpha_{1}$ and airway size and shape}

In this study, the average $\alpha_{1}$ angle was significantly greater in the severe OSA group than in the other groups (Table 2). Univariate correlation analysis showed that a large $\alpha_{1}$ angle was associated with a more oblique airway shape from the soft palate down to the level of the epiglot tip $\left(R_{3-6}\right)$, and a larger CSA at the most caudal three levels (E, F, and G planes) (Table 3). The control group had more elevated coronal CSAs (in the A and D planes) than in the OSA group. At the caudal levels (E and $\mathrm{G}$ planes), no differences were observed between groups apart from a larger CSA in the F plane in the severe OSA group (Table 2). After taking into account the significance of the average variation in airway dimensions and the results of the correlation analysis, it is clear that it is at the lower levels of the airway that physiological adjustment achieves the greatest compensatory effect. At the level corresponding to the base of the epiglottis ( $\mathrm{G}$ plane) and the tongue base (E plane), the CSA exhibited no statistically significant difference in the value of the mean among the groups. The CSA at the level of the tip of the epiglottis ( $\mathrm{F}$ plane) was seen to be greater, in all likelihood because the $\alpha_{1}$ angle was extended in the group of OSA sufferers. Moving in a coronal direction towards the soft palate (CSA at A), the diameters were seen to be reduced in the group of severe OSA patients (Table 2). Whilst patients with OSA can bring the size of the airway caudally back to a normal level by extending their heads, this manoeuvre was ineffective in increasing airway size when viewed at the more caudal portion, i.e. at velar level. Such a result is understandable when the elementary geometry of the region is considered: there is an arc produced by having the head tilt on the cervical vertebrae at the level of the atlanto-occipital joint. The point at which curvature is greatest will be that most distant from the fulcrum ${ }^{[10]}$ By contrast, Polo et al. demonstrated that possession of a bigger hypopharynx may worsen OSA. One possibility is that a relatively massive hypopharynx may render the palate susceptible to inspiratory suction, tending to cause it to collapse. ${ }^{[21]}$

\section{Hyoid bone position, length of the root of the tongue, and epiglot angle}

In the current study, the Valperp length was longer in the severe OSA group. Sufficient distance between the cervical vertebrae and the mandible must exist for the airway to remain fully patent. ${ }^{[22]} \mathrm{A}$ large $\alpha_{1}$ angle can compensate for defects through traction on the hyoid and epiglottis (via the hyo-epiglottic ligament) forwards from the posterior wall of the pharynx, nullifying the occlusive effect on the airway of a greater tongue length than usual. In OSA patients, since this physiological mechanism is weakened when the patient is asleep, gravity may make the tongue fall backwards and block the airway. ${ }^{[12]}$ It is possible to interpret these findings as showing the way patients make physiological compensatory adjustments by increasing the CC angulation and thereby elevating the base of the tongue and epiglottis away from the posterior wall of the pharynx to increase the patency of the airway (Fig. 3). ${ }^{[10]}$

OSA is a multifactorial disorder: age, sex, and BMI are known risk factors. ${ }^{[1,2,23]}$ After adjusting for BMI and age, the $\alpha_{1}$ angle was correlated with OSA severity and increases in the Valperp, MP-H distance, $\alpha_{2}$ angle, and the two most caudal airway CSAs (E and G planes) (Table 3). However, a correlation between the shape of the airway $\left(R_{3-6}\right)$ and CSA in the F plane was no longer observed (Table 3).

Despite the limitations of our study (patients having a neutral head position and being in an awake state), it is apparent that if the upper airway takes on a particular an- 


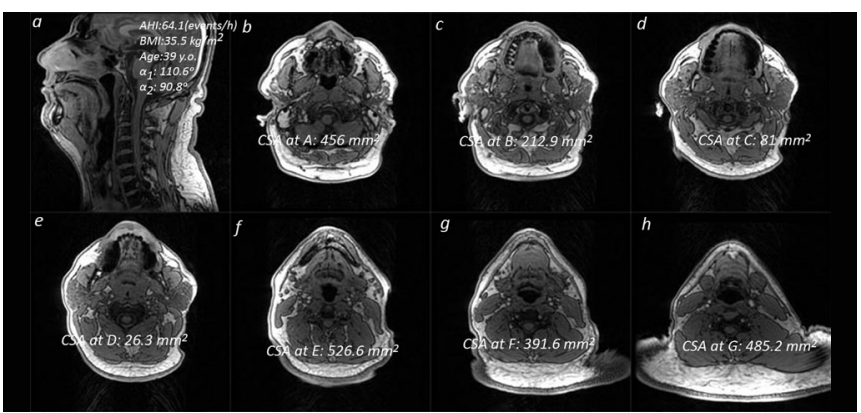

Fig 3. T1-weighted MRI scans of a severe OSA subject. (a) Midsagittal and in transverse sections, (b) A plane, (c) B plane, (d) C plane, (e) D plane, (f) E plane, (g) F plane, and (h) G plane. AHI score, BMI, age, $\alpha 1, \alpha 2$ angles, and CSAs are marked on the image. Note CSA in E and G planes is larger than in the A plane. The compensatory postural stretching is visible and the epiglot is almost in the vertical plane.

atomical topography, for example when the CSA in the A plane is diminished, as well as if risk factors like obesity and older age are present, certain physiological adaptations lead to OSA patients adopting a neutral head posture (Fig. $2,3)$. These findings are in line with with earlier research that has shown a physiological mechanism compensates an obstructed airway by acting via posture in OSA patients whilst awake yet supine. The response produces the greatest compensatory effect lower down within the pharyngeal portion of the airway. However, although severe OSA patients are at risk of having a larger $\alpha_{1}$ angle, the $\alpha_{1}$ angle may vary across the entire spectrum of OSA cases. To put it differently, CC extension and FHP do not invariably correlate with severe OSA. ${ }^{[12]}$

\section{Efficacy of OSA therapies}

An earlier study examined the relationship between hypo- glossal activation, movement of the upper airway movement and the action of moving the tongue passively through pushing the mandible forward and retropalatal opening. ${ }^{[24]}$ We expect that OSA therapies such as surgery (uvulopalatopharyngoplasty [UPPP], palatal advancement, lateral pharyngoplasty), mandibular advancement and stimulation could reduce or normalize the $\alpha_{1}$ angle via a pulling and stretching effect at the root of the tongue and HY bone, as well as via epiglot release and caudal airway CSA normalisation. It is essential for the anatomy to be precisely understood both pre- and post-surgically to improve knowledge about the disease processes in OSA and to evaluate how different therapeutic approaches succeed. Successful therapies should alter CC extension-related mechanisms and the size and shape of the airway, especially at lower levels, and should be considered when evaluating the pathophysiology of OSA patients.

\section{Conclusions}

The length of the radix linguae, MP-H distance, and epiglot angle are all associated with the angle of inclination of the cervical column in the neutral head posture during MRI acquisition in OSA patients. A larger CC inclination angle gave rise to a larger and more oblique airway at lower airway planes and should be considered as an adaptive postural mechanism that maintains airway adequacy in cases of OSA. If this mechanism is absent or attenuated whilst the patient is asleep, the tongue may lapse back and occasion a collapsed airway. Clinicians should be aware of the adaptive physiological mechanisms associated with CC inclination when evaluating OSA patients and responses to different treatment modalities. 


\section{References}

1. Prisant LM, Dillard TA, Blanchard AR. Obstructive sleep apnea syndrome. J Clin Hypertens. 2006;8:746-50.

2. Guilleminault C, Tilkian A, Dement WC. The sleep apnea syndromes. Annu Rev Med. 1976;27:465-84.

3. Ciscar MA, Juan G, Martínez V, Ramón M, Lloret T, Mínguez J, Armengot M, Marín J, Basterra J. Magnetic resonance imaging of the pharynx in OSA patients and healthy subjects. Eur Respir J. 2001;17(1):79-86.

4. Schwab RJ, Gefter WB, Hoffman EA, Gupta KB, Pack AI. Dynamic upper airway imaging during awake respiration in normal subjects and patients with sleep disordered breathing. Am Rev Respir Dis. 1993;148(5):1385400.

5. Suratt PM, Dee P, Atkinson RL, Armstrong P, Wilhoit SC. Fluoroscopic and computed tomographic features of the pharyngeal airway in obstructive sleep apnea. Am Rev Respir Dis. 1983;127:487-92.

6. Lenza MG (1), Lenza MM, Dalstra M, Melsen B, Cattaneo PM. An analysis of different approaches to the assessment of upper airway morphology: a CBCT study. Orthod Craniofac Res. 2010;13(2):96-105. doi:10.1111/ j.1601-6343.2010.01482.x.

7. Abbott MB, Donnelly LF, Dardzinski BJ, Poe SA, Chini BA, Amin RS. Obstructive sleep apnea: MR imaging volume segmentation analysis. Radiology. 2004;232:889-95.

8. Schwab RJ. Upper airway imaging. Clin Chest Med. 1998;19:33-54.

9. Di Carlo G (1), Polimeni A, Melsen B, Cattaneo PM. The relationship between upper airways and craniofacial morphology studied in 3D. A CBCT study. Orthod Craniofac Res. 2015;18:1-11. doi: 10.1111/ocr.12053.

10. Solow B, Skov S, Ovesen J, Norup PW, Wildschiødtz G. Airway dimensions and head posture in obstructive sleep apnoea. Eur J Orthod. 1996;18:571-9.

11. Sonnesen L, Petersson A, Berg S, Svanholt P. Pharyngeal airway dimensions and head posture in obstructive sleep apnea patients with and without morphological deviations in the upper cervical spine. J Oral Maxillofac Res. 2017;30;8:e4. doi: 10.5037/jomr.2017.8304.

12. Ozbek MM, Miyamoto K, Lowe AA, Fleetham JA. Natural head posture, upper airway morphology and obstructive sleep apnoea severity in adults. Eur J Orthod. 1998;20:133-43.

13. Iber C, Ancoli-Israel S, Chesson A, Quan S (2007) The AASM manual for the scoring of sleep and associated events: rules, terminology and technical specifications. American Academy of Sleep Medicine, Westchester

14. Berry RB, Budhiraja R, Gottlieb DJ, Gozal D, Iber C, Kapur VK, Marcus
CL, Mehra R, Parthasarathy S, Quan SF, Redline S, Strohl KP, Ward SLD, Tangredi MM (2012) Rules for scoring respiratory events in sleep: update of the 2007 AASM manual for the scoring of sleep and associated events. J Clin Sleep Med 8:597-619. https:// doi.org/10.5664/jcsm.2172

15. Ono T, Otsuka R, Kuroda T, Honda E, Sasaki T.J Dent Res. Effects of head and body position on two- and three-dimensional configurations of the upper airway. 2000;79:1879-84.

16. Pirilä-Parkkinen K(1), Pirttiniemi P, Pääkkö E, Tolonen U, Nieminen $P$, Löppönen H. Pharyngeal airway in children with sleep-disordered breathing in relation to head posture. Sleep Breath. 2012;16:737-46. doi:10.1007/ s11325-011-0569-y.

17. Zhang W (1), Song X, Masumi SI, Tanaka T, Zhu Q. Effects of head and body positions on 2- and 3-dimensional configuration of the oropharynx with jaw protruded: A magnetic resonance imaging study. Oral Surg Oral Med Oral Pathol Oral Radiol Endod. 2011;111:778-84. doi:10.1016/j.tripleo.2011.02.019.

18. Gurani SF, Di Carlo G, Cattaneo PM, Thorn JJ, Pinholt EM. Effect of head and tongue posture on the pharyngeal airway dimensions and morphology in three-dimensional imaging: A systematic review. J Oral Maxillofac Res. 2016;31;7:e1. doi: 10.5037/jomr.2016.7101.

19. Solow B, Ovesen J, Nielsen PW, Wildschiødtz G, Tallgren A. Head posture in obstructive sleep apnoea. Eur J Orthod. 1993;15:107-14.

20. Tangugsorn V, Skatvedt O, Krogstad O, Lyberg T. Obstructive sleep apnoea: a cephalometric study. Part I. Cervico-craniofacial skeletal morphology. Eur J Orthod. 1995;17:45-56.

21. Polo OJ, Tafti M, Fraga J, Porkka KV, Déjean Y, Billiard M. Why don’t all heavy snorers have obstructive sleep apnea? Am Rev Respir Dis. 1991;143:1288-93.

22. Koski K, Lähdemäki P. Adaptation of the mandible in children with adenoids. Am J Orthod. 1975 Dec;68(6):660-5.

23. Ünlü M, İriz A, Doğan BA, Dinç ASK, Dursun E, Eryılmaz A, Acar A. Relationship between obesity with symptoms and findings of obstructive sleep apnea syndrome. J Med Updates 2014;4:11-15 doi:10.2399/ jmu. 2014001003

24. Safiruddin F, Vanderveken OM, de Vries N, Maurer JT, Lee K, Ni Q, Strohl KP (2015) Effect of upper-airway stimulation for obstructive sleep apnea on airway dimensions. Eur Respir J 45:129-138. https://doi. org/10.1183/09031936.00059414 